\title{
RESENHA CRÍTICA: PENSANDO AS RELAÇÕES RACIAIS E A ESCOLARIZAÇÃO DE FAMÍLIAS CAMPONESAS
}

\author{
CRITICAL REVIEW: THINKING RACIAL RELATIONS AND SCHOOLING FAMILIES
}

\section{REVISIÓN CRÍTICA: PENSAR LAS RELACIONES RACIALES Y LAS FAMILIAS ESCOLARES}

\author{
PATRÍCIA GERALDA RESENDE SOUZA ${ }^{1}$ \\ ORCID: https://orcid.org/0000-0002-2125-0258 \\ ÉCIO ANTÔNIO PORTES ${ }^{2}$ \\ ORCID: https://orcid.org/0000-0003-2760-4667
}

CAMPOS, Alexandra Resende. Relações Raciais e Escolarização de Famílias Camponesas. Curitiba: Editora Appris, 2019.

Alexandra Resende Campos é graduada em Pedagogia pela Universidade Federal de São João del-Rei e mestre e doutora em Educação pela Universidade Federal Fluminense (UFF). Suas pesquisas seguem a linha: Diversidade, Desigualdades Sociais e Educação. Alexandra é docente do Departamento de Educação da Universidade Federal de Ouro Preto (DEED-UFOP), atua no campo da Sociologia da Educação e tem como foco de seus estudos a dinâmica escolar das famílias camponesas, levando em consideração seus estilos de vida e todas as ações empreendidas para garantirem o acesso e a permanência dos filhos na escola.

A obra "Relações Raciais e Escolarização de Famílias Camponesas"(CAMPOS, 2019) discorre sobre um tema atual e ainda pouco explorado no campo da Educação: relações entre escolarização, origem social e pertencimento racial. Nesse contexto, problematiza se as práticas de escolarização empreendidas pelas famílias para manterem os filhos na escola diferenciam-se de acordo com o pertencimento racial. Cabe destacar que, ao lidar com famílias camponesas, a autora moveu uma temática relevante e pouco mobilizada nos estudos da área, até hoje. No caso, investigou os habitantes do meio rural.

É pertinente elucidar aqui que a autora define práticas de escolarização como as práticas empreendidas pelas famílias que influenciam, direta ou indiretamente, o processo de escolarização e a trajetória escolar dos filhos, práticas como fazer o dever, ser bom aluno, participar das aulas, respeitar a professora, acompanhar a vida escolar dos filhos, participar das reuniões escolares, participar dos eventos e festas da escola, ter um ambiente favorável ao cumprimento das atividades escolares, dentre outras. São práticas como essas que evidenciam o nível de mobilização das famílias em relação à escolarização dos filhos.

É importante mencionar que o livro é resultado de anos de pesquisa. A autora se interessou por esse tema em 2005, quando foi bolsista de iniciação científica do CNPq (Conselho Nacional de

\footnotetext{
${ }^{1}$ Mestranda do Programa de Pós-Graduação em Educação da Universidade Federal de São João del-Rei e membro do Núcleo de Estudos e Pesquisas Sócio Históricas em Educação (NEPSHE). São João del-Rei, MG, Brasil. <pgresendes@gmail.com>

${ }^{2}$ Professor Titular da Universidade Federal de São João del-Rei. São João del-Rei, MG, Brasil.. <eaportes@gmail.com>
} 
Desenvolvimento Científico e Tecnológico) na pesquisa "As práticas de escolarização de famílias rurais com filhos em idade escolar: o caso do povoado de Goiabeiras, São João del-Rei, MG”, realizada no período de 2005-2008, sob a orientação do professor Dr. Écio Antônio Portes.

O objeto de pesquisa do livro se situa na área de Sociologia da Educação, mais especificamente o campo das trajetórias e as estratégias escolares de famílias camponesas. Trata-se de um estudo realizado a partir de análises de situações concretas, ao cuidar das histórias particulares de cada família investigada. A autora dialoga com diversos autores, mas como inspirações teóricas utilizadas mais atinentes a Clark, 1983; Lahire, 2008; Lareau, 2007; Montandon, 1994; Portes, 2000; Thin, 2006; Vianna, 2000, pois foram estes autores que contribuíram para a orientação teórica dos eixos temáticos apresentados no livro.

A abordagem teórico-metodológica utilizada foi a etnografia, baseada em uma intensa imersão no campo de pesquisa pela autora. Nesse caso, foi feito um acompanhamento sistemático da rotina das famílias, com duração de uma semana. Como procedimentos metodológicos foram utilizadas a entrevista semiestruturada e a observação participante. Além disso, vale ressaltar o fato de que a autora já conhecia o povoado ao participar de pesquisas anteriores desenvolvidas no mesmo, desde 2005. Essa inserção prolongada propiciou maior intensidade nas relações com os familiares e melhor compreensão dos fenômenos sociais ali vivenciados. Não ser uma "estranha" nesse povoado propiciou ainda uma economia dos tempos necessários para inserção em diferentes lares.

As seis famílias escolhidas para o estudo no livro residem no povoado de Goiabeiras e foram selecionadas com base em dados referentes ao perfil socioeconômico e cultural de 44 famílias que possuíam filhos matriculados na Escola Municipal de Goiabeiras, no ano de 2005. As famílias que compõem os perfis construídos foram eleitas a partir dos seguintes critérios: três famílias (uma negra, uma mestiça e uma branca) cujos filhos estivessem em idade escolar regular e outras três (uma negra, uma mestiça e uma branca) cujos filhos apresentassem defasagem escolar de dois anos, para que fosse possível contrastá-las entre si, reciprocamente, relacionar, comparar e analisar. No entanto, para a família branca com defasagem foi considerada uma defasagem escolar branda, pois não se encontrou família branca na situação planejada. O livro foi organizado em cinco capítulos, além da Introdução e Referências.

No capítulo I, a autora faz uma minuciosa caracterização do lugar pesquisado e aponta aspectos de ordem metodológica, como o suporte teórico escolhido, a seleção, classificação e pertencimento racial das famílias pesquisadas e, ainda, esclarece sua relação com as famílias, moradores e a equipe pedagógica da Escola Municipal de Goiabeiras.

Já os capítulos II, III e IV cuidam da apresentação e caracterização das famílias, de modo que cada capítulo se refere à construção do perfil de duas famílias, sendo famílias negras, famílias mestiças e famílias brancas, respectivamente. Cada capítulo é baseado em seis eixos temáticos: (i) caracterização sociocultural; (ii) cotidiano da família; (iii) redes de relações; (iv) percepção racial; (v) vínculo com a vida escolar dos filhos; (vi) família e escola: o que pensam uns dos outros? Ao final de cada capítulo a autora realiza uma análise comparativa entre as duas famílias aparentemente iguais de cada seção com o intuito de compreender as diferenças referentes ao desempenho escolar dos filhos e às práticas de escolarização empreendidas por elas.

Por fim, o capítulo $V$ se ocupa em responder à pergunta inicial: as práticas de escolarização empreendidas pelas famílias se diferenciam de acordo com o pertencimento racial? Com esse intuito a autora elenca novas chaves de análise, que se relacionaram detidamente com o foco do estudo. Essas chaves fazem referências às seguintes questões: pertencimento racial; configuração familiar e itinerários de escolarização; raça, classe e escolarização.

No que se refere ao 'pertencimento racial', a autora analisa a classificação racial das famílias e as situações relatadas por elas no que se refere à discriminação. Nessa abordagem ficou nítido que a valorização simbólica pelo ideal de brancura ainda prevalece. Com efeito, a autoclassificação da cor da pele ficou à mercê de incômodos e embaraços por parte dos entrevistados, principalmente daqueles que configuravam uma família mista, em que um dos cônjuges era branco ou pardo, e o outro, preto. Já nas famílias que se autoclassificaram como brancas não se notaram constrangimentos. No entanto, para além de casos de discriminação racial, houve relatos dos entrevistados que vivenciaram também algum episódio de discriminação devido às condições econômicas das famílias. 
$\mathrm{Na}$ análise da 'configuração familiar e itinerários de escolarização', a autora analisou os fatores que apresentaram alta mobilização em relação ao acompanhamento do processo de escolarização dos filhos. A autora mostrou uma série de circunstâncias que nortearam as práticas de escolarização das crianças, que foram organizadas em quatro categorias.

A primeira, 'escolarização das famílias', aponta para a influência do capital escolar significativo ou não da família sobre os filhos. Nesse contexto, pais que vivenciaram experiências escolares que atribuem como positivas alimentavam o desejo de que os filhos prosseguissem nos estudos; já os pais que tinham uma memória negativa da trajetória escolar tenderam a ser menos esperançosos em relação ao futuro escolar dos filhos.

A segunda categoria discorre sobre as 'condições socioeconômicas'. Aqui, a autora aborda como as condições financeiras interferiam na rotina das famílias: uma rotina estável e tranquila favorecia a forma de lidar com a escolarização, ao passo que, já uma rotina instável podia interferir negativamente no processo de escolarização das crianças.

A terceira categoria, 'relações internas e externas mantidas pela família', diz respeito ao tipo de relação estabelecida entre os familiares, ao controle dos pais sobre os filhos, ao envolvimento religioso das famílias e às redes de relações externas ao povoado. Nesse ponto, a análise feita gira em torno da forma de diálogo estabelecida entre os membros internos e externos às famílias. Mostra que o nível de envolvimento entre os integrantes das famílias influencia o comportamento das crianças e a maneira como elas se relacionam dentro e fora de casa, como elas atuam nos diversos espaços sociais.

A quarta categoria, a 'escolarização dos filhos', analisa a visão das professoras sobre as famílias, o sentido da escola para a vida dos filhos e o acompanhamento dos pais no processo de escolarização dos mesmos. Evidenciou-se que todas as famílias pesquisadas são interessadas pela vida escolar dos filhos, em diferentes níveis. As famílias reconhecem a escola "como uma instituição importante para a vida de suas crianças".

Por último, a chave de análise 'raça, classe e escolarização' se remete à questão que moveu toda a pesquisa. É neste quesito que se evidencia que a questão racial não influenciou as práticas de escolarização empreendidas pelas famílias pesquisadas, pois, nos três grupos de famílias (negras, mestiças e brancas) foi possível notar pais que empreenderam práticas sistematizadas, além de demonstrarem alta mobilização no que se refere ao acompanhamento da vida escolar dos filhos.

A influência do pertencimento de classe social na rotina diária das famílias e no acompanhamento adotado no processo de escolarização dos filhos não foi tão importante. Nesse caso, as famílias investigadas pertencentes ao mesmo extrato social, a mesma localidade e que, praticamente, desfrutam das mesmas instâncias de socialização escolar adotaram práticas distintas. Isso permitiu afirmar que a classe social não é determinante, e isso vai ao encontro da teoria da reprodução bourdieusiana. Ficou evidente que as desigualdades escolares não estão intrinsecamente ligadas à posição de classe.

De um modo geral, o contato com a obra aqui resenhada potencializa reflexões ao se pensar sobre as estratégias utilizadas pelas famílias aparentemente iguais, econômica e culturalmente, pelo fato de apresentarem práticas divergentes quanto à escolarização dos filhos. É importante também por explicitar que o quesito pertencimento racial não interfere na forma como cada família interage com o saber. O pertencimento racial não diz sobre as práticas escolares utilizadas pelas famílias, não é determinante de seus movimentos frente à escola.

Fica nítido, no contexto da obra, que o que interfere e altera o desempenho dos filhos "para lá" ou "para cá" é a forma como as famílias e as crianças conduzem a relação com a escola, com os estudos e o meio nos quais elas se inserem. As práticas de escolarização não são condicionadas pelo pertencimento racial. Aliás, elas são norteadas por uma rede de diferentes contextos, sujeitos e interrelações, e é isso que parece conduzir a relação com os estudos. É o conjunto de circunstâncias atuantes que delineiam os caminhos a serem trilhados.

No ponto de encontro entre família e escola, as reflexões da autora permitem o diálogo ancorado no exame crítico das situações específicas das práticas de escolarização empreendidas pelas famílias, sem desconsiderarem as questões e situações sociais que as constituem.

Com este livro, consideramos que uma nova força teórica se instala no campo da Educação, anunciando a capacidade de refletir sobre temas complexos, como as relações raciais e práticas escolares. Para além disso, a obra contempla também o meio rural, que ainda é pouco abordado nos estudos 
acadêmicos que se ocupam com as práticas de escolarização de famílias pertencentes ao mundo não urbano. Eis a relevância e originalidade do estudo que se dá a conhecer.

Por fim, ressalta-se que se trata de uma obra que traz contribuições importantes para entender as relações raciais e o processo de escolarização de famílias camponesas. Com uma escrita bem organizada, permite uma leitura dinâmica e agradável ao leitor. É importante dizer que, ao iniciar o livro pela apresentação de uma capa sugestiva que remete à diversidade, ao direito efetivo de aceso à escola e à educação por todos os sujeitos, a autora já se coloca em relação aos próprios anseios. Dessa forma, é pertinente indicar esta leitura ao público da área da Educação e áreas afins, ou ainda aos curiosos e inquietos que apostam na Educação como o caminho da garantia de direitos a uma educação pública, gratuita, democrática, de qualidade e socialmente referenciada.

\section{Referência}

CAMPOS, Alexandra Resende. Relações Raciais e Escolarização de Famílias Camponesas. Curitiba: Editora Appris, 2019.

Submetido: $19 / 11 / 2019$

Aprovado: 05/03/2020 